\title{
In vivo study on the effects of microcystin-LR on the apoptosis, proliferation and differentiation of rat testicular spermatogenic cells of male rats injected i.p. with toxins
}

\author{
Yuan Zhou'1,2,3, Yu Chen ${ }^{1,2,3}$, Mingming Yuan 1,2,3, Zou Xiang ${ }^{4}$ and Xiaodong Han 1,2,3 \\ ${ }^{I}$ Immunology and Reproduction Biology Laboratory, Medical School, Nanjing University, \\ Nanjing, Jiangsu 210093, China \\ 2 Jiangsu Key Laboratory of Molecular Medicine, Nanjing University, Nanjing, Jiangsu 210093, China \\ ${ }^{3}$ State Key Laboratory of Analytical Chemistry for Life Science, Nanjing University, \\ Nanjing, Jiangsu 210093, China \\ ${ }^{4}$ Department of Microbiology and Immunology, Mucosal Immunobiology and Vaccine Research Center, \\ Institute of Biomedicine, University of Gothenburg, Gothenburg, Sweden
}

(Received May 30, 2013; Accepted July 20, 2013)

\begin{abstract}
Microcystin-leucine arginine (MC-LR), a cyclic heptapeptide produced by cyanobacteria, has strong reproductive toxicity. The present study was designed to elucidate the mechanism of declines in sperm quality as a result of exposure to MC-LR by using spermatogenic cells as a model system. MC-LR was intraperitoneally administered to male rats daily at 0,50 and $100 \mu \mathrm{g} / \mathrm{kg}$ body weight for one week. Results showed that changes occurred in the structural of testis, the tubular diameter and the relative weight of the testes was significantly decreased following treatment with $100 \mu \mathrm{g} / \mathrm{kg}$. Major differences in apoptosis and proliferation of testicular cells were observed at the $100 \mu \mathrm{g} / \mathrm{kg} \mathrm{MC}$-LR. The gene expression levels of testis-specific histone 2B (TH2B) and transition protein 2 (TP2) were both significantly decreased. Meanwhile, the stem cell factor receptor (c-kit) was increased after exposure to 50 or $100 \mu \mathrm{g} / \mathrm{kg}$ MC-LR. This study demonstrated that MC-LR can alter the apoptosis, proliferation and differentiation of spermatogenic cells in vivo.
\end{abstract}

Key words: Microcystin-LR, Spermatogenic cells, Seminiferous tubular diameter, Apoptosis, Proliferation, Differentiation

\section{INTRODUCTION}

Microcystins (MCs) are a class of cyclic heptapeptide compounds produced by several genera of freshwater cyanobacteria, and have received worldwide concern in recent decades (Carmichael et al., 2001). MCs can be found in many freshwater bodies, which are sources for drinking water, due to the frequent occurrence of cyanobacterial blooms (Harada, 1999). The concentrations of total MCs may reach up to $1,300 \mu \mathrm{g} / 1$ in surface waters (Hermann Fromme, 2000). One study revealed that the concentrations of MCs in the blooming lakes in the United States ranged from $10 \mu \mathrm{g} / 1$ to $500 \mu \mathrm{g} / 1$ (Backer et al., 2010). Thus, MCs may pose a health hazard to animals and humans higher up in the food chain because of the accumulation of MCs in aquatic creatures (Chen and Xie,
2005; Chen et al., 2005; Xie et al., 2004). MCs were identified for the first time in the serum of a chronically exposed human population together with indication of hepatocellular damage in a recent study (Chen et al., 2009). The World Health Organization (WHO) set a provisional guideline which allows maximally $1 \mu \mathrm{g} / \mathrm{l} \mathrm{MCs}$ in drinking water (WHO, 2004). So far, more than 100 different structural analogs of MCs have been identified, with microcystin-leucine arginine (MC-LR) being the most toxic and the most commonly encountered variant (Dietrich and Hoeger, 2005).

MCs have been well characterized as strong inhibitors of cellular serine/threonine protein phosphatases (PP) 1 and 2A in hepatocytes (Craig et al., 1996). The inhibition is achieved through interaction with diverse molecular targets resulting in hyperphosphorylation of key proteins

Correspondence: Xiaodong Han (E-mail: hanxd@nju.edu.cn) 
that regulate cell function. Current studies have confirmed that microcystins may generate nephrotoxicity and especially hepatotoxicity, as they are predominantly absorbed, transported and accumulated into liver (Svircev et al., 2010; Wang et al., 2010). Recently, some studies indicate that the gonads might be another important target organ of MCs (Chen and Xie, 2005; Chen et al., 2005, 2011; Li et al., 2008). A certain amount of MCs is still present in the gonads at $24 \mathrm{hr}$ after intraperitoneal injection of $\mathrm{MC}$ extracts at a dose of MC-LR $80.5 \mathrm{mg} / \mathrm{kg}$ body weight, suggesting its resistance to elimination from the gonad. Our previous in vivo studies have demonstrated that treatment with $\mathrm{MC}-\mathrm{LR}$ results in substantial toxicity to male reproduction with declines in sperm quality, decreased levels of serum testosterone, and injury to the testis (Chen et al., 2011; Li et al., 2008), which suggests that MCs are toxic to the male mammalian reproductive system. However, regardless of recent achievements, the mechanisms underlying $\mathrm{MC}$ reproductive toxicity remain elusive and little is known about the mechanisms of declines in sperm quality.

As is known, the spermatogenic cells, Sertoli cells and Leydig cells are three main kinds of important cells in the testis. Specifically, Sertoli cells provide necessary nutrition for spermatogonia, while Leydig cells synthesize and secrete testosterone into seminiferous tubules to promote spermatogenesis (Bellve et al., 1977; Svechnikov et al., 2010). MCs can cause damage to Sertoli cells directly and Leydig cells indirectly (Li and Han, 2012; Wang et al., 2012; Xiong et al., 2009). Nevertheless, there is no in vivo evidence that MC-LR can affect spermatogenic cells, the most important cells in the testis. Toxicity studies demonstrate that MCs may compromise sperm quality affecting spermatogenic cells directly during spermatogenesis (Sohoni et al., 2001). Therefore, in view of the adverse effects of MC-LR on sperm concentration and quality our concern was focused on its toxic effects on spermatogenic cells in the process of spermatogenesis. During spermatogenesis, diploid spermatogonia divide mitotically several times to provide a population of spermatocytes that proceed through meiosis to give birth to haploid spermatids which undergo morphological alterations leading to spermatozoa (White-Cooper and Bausek, 2010). The apoptosis, proliferation and differentiation of spermatogenic cells are involved in the entire process of spermatogenesis. Previous research suggests that these events occur spontaneously in rodents as well as in response to endocrine disruption and exposure to various environmental agents and chemicals (Billig et al., 1995; Brinkworth et al., 1995; Tapanainen et al., 1993). To date, there is no report clarifying whether MCs can affect apop- tosis, proliferation and differentiation of spermatogenic cells.

Given these findings, it is interesting to find out whether MC-LR has toxicity on spermatogenic cells directly in vivo. To this end, we undertook to detect cell apoptosis, proliferation and differentiation by means of immunohistochemistry and quantitative real-time PCR. The primary aim of this study was to investigate the mechanisms of decreased sperm quality following exposure to MC-LR and provide a better understanding of the mechanisms of MC-LR-mediated male reproductive toxicity.

\section{MATERIALS AND METHODS}

\section{Main chemicals}

MC-LR with a purity of $>96 \%$ was purchased from Alexis Biochemicals (Lausen, Switzerland). The in Situ Cell Death Detection Kit (POD) was purchased from Roche Co. (Berlin, Germany). Column animal RNAout kits were purchased from Tiandz, Inc. (Beijing, China). Easyscript first-strand cDNA synthesis super mix was obtained from Beijing TransGen Biotech Co. Ltd. (Beijing, China). Primer pairs were purchased from Nanjing Genscript Biotechnology (Nanjing, China). DNase and Proteinase K were purchased from SigmaAldrich (Munich, Germany).

Rabbit anti Rat c-kit antibody and Alexa Fluor 594 goat anti rabbit IgG were purchased from Santa Cruz (LA, CA, USA). Mouse anti proliferating cell nuclear antigen (PCNA) antibody, Cy3 goat anti mouse IgG and mouse anti $\beta$-actin were bought from Abcam (Cambridge, United Kingdom). 4', 6-diamidino-2-phenylindole (DAPI), HRP -conjugated goat anti-rabbit IgG and HRP-conjugated goat anti-mouse IgG were obtained from Boster Bio-technology Co. Ltd. (Wuhan, China). All the reagents were of analytical grade.

\section{Animals and treatment}

Healthy male Sprague-Dawley rats $(n=30)$ weighting from 40-50 $\mathrm{g}$ and aged 17 to 18 days were obtained from Sino-British Sippr-BK Lab. Animal Ltd., Co. (Shanghai, China), and were housed in the Nanjing University animal facility. Rats were fed with commercial rat chow and water ad libitum and kept on a $12 \mathrm{hr}$ : $12 \mathrm{hr}$ light-dark cycle. After one week of acclimation, the 24-25-day rats were randomly divided into three groups (group A, B and C) with 10 animals in each group.

The Intraperitoneal (i.p.) lethal dose $50\left(\mathrm{LD}_{50}\right)$ of MC-LR in rat was determined by intraperitoneal injections according to the up-down method of small animals (Dawson, 1998). Rats in groups B and C received an 
Toxic effects of microcystin-LR on spermatogenic cells

intraperitoneal injection of MC-LR at doses of $50 \mu \mathrm{g} / \mathrm{kg}$ $\left(1 / 3 \mathrm{LD}_{50}\right)$ and $100\left(2 / 3 \mathrm{LD}_{50}\right) \mu \mathrm{g} / \mathrm{kg}$ body weight every day for 7 days according to the $\mathrm{LD}_{50}$ and the previous studies (Miura et al., 1991). The rats in the control group (group A) were injected daily with $7.5 \mathrm{ml} \cdot \mathrm{kg}$ body weight $0.9 \%$ saline solution. MC-LR was dissolved in a minimum amount of methanol $(0.1 \%)$ and diluted to the required concentration in normal saline. The final volum was equal to the saline volume used in the control group. The animals were handled in accordance with guidelines approved by the Experimentation Ethics Review Committee of Nanjing University (ethics approval no. A9089).

\section{Histopathological evaluation}

The testes were fixed over night at $4{ }^{\circ} \mathrm{C}$ in $4 \%(\mathrm{w} / \mathrm{v})$ paraformaldehyde in phosphate-buffered saline (PBS) $(\mathrm{pH}=7.4)$. They were dehydrated successively using $30 \%, 50 \%, 75 \%, 80 \%, 85 \%, 90 \%, 95 \%$ and $100 \%$ ethanol. Then they were embedded in paraffin, sectioned at $5 \mu \mathrm{m}$ and stained with hematoxylin and eosin (H\&E) for light microscopic examination.

\section{Tubular diameter measurements}

The method used for determining tubular diameter was based on previously published methods (Katerina Kovačevič, 2006). Testes from 24-25-day rats (5 rats from each group) exposed to MC-LR for 7 days were cut on a microtome at $5 \mu \mathrm{m}$ and stained with hematoxyline and eosin using standard procedures. Seminiferous tubular diameter was measured at 20x magnification using the Image-Pro plus Version 6.0 software. The diameters of 50 randomly chosen tubules were measured in each testis from each animal. Only tubules considered round by eye examination were used for the diameter measurement to avoid oblique cutting of tubules. The testis relative weights were calculated according to the observed net weight gain and testis absolute weights.

\section{Measurement of testicular cell apoptosis via TUNEL staining}

TUNEL was carried out following the producer's directions. The paraffin embedded testicular tissues were sectioned at $5 \mu \mathrm{m}$ and placed on the glass slides at $37^{\circ} \mathrm{C}$ over night, followed by storage at $4^{\circ} \mathrm{C}$ until standard processing. Briefly, $5 \mu \mathrm{m}$ sections of testicular tissues were stained by H\&E followed by deparaffinization, rehydration, fixation in 4\% paraformaldehyde in PBS, permeabilizaion with Proteinase K, pre-equilibration, and labeling of DNA strand breaks with reaction mixture for $1 \mathrm{hr}$. Samples were visualized after DAPI nuclear stain in the mounting medium using a confocal microscope
(Fluoview FV10i, Japan) to detect the localized green fluorescence of apoptotic cells.

Positive TUNEL POD labeling was prepared using DNase treatment. After pretreatment, histological sections were incubated with DNase at $37^{\circ} \mathrm{C}$ for $10 \mathrm{~min}$ to induce DNA strand breaks. Negative control was carried out by omitting terminal transferase from the labeling procedure (label solution only instead of TUNEL reaction mixture).

\section{Detection of testicular cell proliferation via immunohistochemistry}

Sections were mounted on slides. Before incubation with primary antibodies, sections were dewaxed, rehydrated in graded ethanol, washed in water and PBS followed by blocking endogenous peroxidase by incubating the section for $10 \mathrm{~min}$ in $3 \% \mathrm{H}_{2} \mathrm{O}_{2}$. After disrupting cell membranes with $0.3 \%$ Triton $\mathrm{X}-100$, the sections were incubated in blocking buffer containing 3\% bovine serum albumin for $30 \mathrm{~min}$. Mouse anti-PCNA antibody (1:200) was applied in a humidified atmosphere and incubated overnight. The fluorochrome-conjugated secondary antibody (1:200) was added and samples were incubated for $60 \mathrm{~min}$ at $37^{\circ} \mathrm{C}$. Nuclei were counterstained with $5 \mu \mathrm{g} / \mathrm{ml}$ DAPI. Finally, slides were mounted with glycerin and visualized using a confocal microscope.

\section{Total RNA extraction and cDNA synthesis}

Total RNA was isolated from each sample using Column Animal RNAout according to the manufacturer's instructions. $2 \mu \mathrm{l}$ total RNA was eluted with $48 \mu \mathrm{l}$ RNasefree water and purity was determined by the quotient of OD at 260/280 nm. The Easyscript first-strand cDNA synthesis super mix kit was used for reverse transcription polymerase chain reaction (RT-PCR). The resultant cDNA was stored at $-20^{\circ} \mathrm{C}$.

\section{Quantitative real-time PCR (Q-PCR)}

The primers were designed based on the gene sequence of Rattus norvegicus present on the NCBI (http://www. ncbi.nlm.nih.gov) to amplify a $150-300 \mathrm{bp}$ section. The sequences of the primer pairs used in this assay are shown in Table 1. Specification of each pair of primers was tested by randomly sequencing four clones, and further confirmed by the melting curve analysis using Q-PCR. Only primers with similar amplification efficiency were used in this experiment. Q-PCR was conducted by amplifying $50 \mu \mathrm{l}$ of diluted cDNA with the SYBR Green Q-PCR kit (Roche) with 7300 Real-Time PCR System (ABI, NY, NY, USA). Cycling conditions were as follows: $10 \mathrm{~min}$ at $95^{\circ} \mathrm{C}, 40$ cycles of $20 \mathrm{sec}$ at $94^{\circ} \mathrm{C}, 25 \mathrm{sec}$ at $60^{\circ} \mathrm{C}$, and $30 \mathrm{sec}$ at $72^{\circ} \mathrm{C}$. Melting curve analysis of the 
Table 1. Primer used for Q-PCR

\begin{tabular}{llll}
\hline & \multicolumn{1}{c}{ Primer sequence (5'-3') } & Sorward \\
\cline { 2 - 3 } Target gene & GCATCACCATCAAAAACGTG & Reverse & 332 \\
\hline c-kit & TGAGACGTTGGAGTGGACAA & GATAGTCAGCGTCTCCTGGC & 152 \\
TH2B & GGCCTCAAAGTCACACCAAT & TTCCCTTCCAAGGTCTTCCT & 205 \\
TP2 & CAACTCCCTCAAGATTGTCAGCAA & GGCATGGACTGTGGTCATGA & 118 \\
GAPDH & & &
\end{tabular}
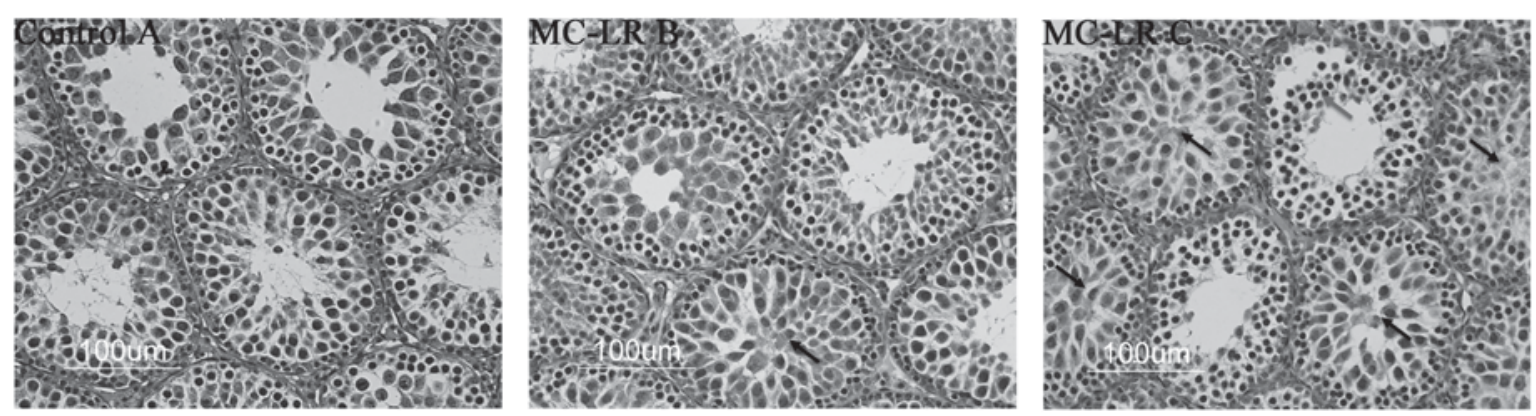

Fig. 1. Effect of MC-LR on the testicular microstructures of male rats. Paraffin sections were prepared from testes of rats exposed to saline (A), MC-LR at $50 \mu \mathrm{g} / \mathrm{kg}$ (B) and $100 \mu \mathrm{g} / \mathrm{kg}$ (C) for 7 days. The sections were stained with H\&E. Bar $=100 \mu \mathrm{m}$. In comparison with control, the spermatogenic epithelium became sparse following treatment with MC-LR at $100 \mu \mathrm{g} / \mathrm{kg}$. The structure of the spermatogenic epithelium was lost, deranged, thinner and blocked after treatment in a dose-dependent manner. The black arrow shows blockage of the seminiferous tubules, while the red arrow shows sparse seminiferous tubules and loss of spermatogenic cells.

amplification products was carried out at the end of each PCR reaction to confirm that a single PCR product was detected. Each sample was run in triplicate, and PCR reactions without the addition of the template were used as blank controls. The relative quantification of the expression of the target genes was measured using Glyseraldehyde-3-phosphate dehydrogenase (GAPDH) mRNA as an internal control, which is reported to be not affected by MCs (Chen et al., 2005; Hudder et al., 2007). After completion of the PCR amplification, data were analyzed by the 7300 Sequence Detection Software (ABI).

\section{Statistical analysis}

The data were expressed as the mean \pm standard error (SE). All calculations and statistical analyses were performed using SPSS for windows version 11.0 (SPSS Inc., Chicago, IL, USA). One-way analysis of variance (ANOVA) was used to analyze the difference between groups, followed by the Dunnett's t-test. $P<0.05$ was regarded as statistically significant.

\section{RESULTS}

\section{Disrupted histopathological structures of rat testicles}

After exposure to MC-LR, rat testicular tissue structure was observed through paraffin sections by H\&E staining (Fig. 1). A regular arrangement of spermatogenic epithelium in seminiferous tubules in control tissues was seen (Fig. 1A). The results demonstrated that the pathologic findings in the $50 \mu \mathrm{g} / \mathrm{kg}$ group changed slightly with no significant difference (Fig. 1B). The spermatogenic epithelium appeared loosened in its organization, and blockage of the seminiferous tubules and the spermatogenic cell arrangement disorder were evident in group $\mathrm{C}$ which was treated with $100 \mu \mathrm{g} / \mathrm{kg}$ MC-LR. In addition, this high dose treatment resulted in sparse seminiferous tubules and loss of spermatogenic cells (Fig. 1C).

\section{The effect of MC-LR on tubular diameter}

Compared to the control group we observed a significant $(\mathrm{P}<0.05)$ decrease in the mean absolute weight of the testes in rats treated with MC-LR (Table 2). At the 
Toxic effects of microcystin-LR on spermatogenic cells

Table 2. Effect of MC-LR on body weight and testes weights of male rats in comparison to control rats

\begin{tabular}{lccc}
\hline Groups & Net weight gain $(\mathrm{g})$ & Testis absolute weights $(\mathrm{g})$ & $\begin{array}{c}\text { Testis relative weights } \\
(\mathrm{g} / 100 \mathrm{~g} \text { weight })\end{array}$ \\
\hline $0 \mu \mathrm{g} / \mathrm{kg}$ MC-LR $(\mathrm{n}=10)$ & $98.03 \pm 3.0$ & $0.85 \pm 0.02$ & $0.88 \pm 0.04$ \\
$50 \mu \mathrm{g} / \mathrm{kg}$ MC-LR $(\mathrm{n}=10)$ & $91.75 \pm 3.6$ & $0.75 \pm 0.03^{*}$ & $0.82 \pm 0.03$ \\
$100 \mu \mathrm{g} / \mathrm{kg}$ MC-LR $(\mathrm{n}=10)$ & $85.42 \pm 3.0 *$ & $0.56 \pm 0.03^{* *}$ & $0.65 \pm 0.04 *$ \\
\hline
\end{tabular}

Data are shown as mean \pm S.E.

$*$ Response that is significantly different from the control $(\mathrm{P}<0.05)$.

** Response that is significantly different from the control $(\mathrm{P}<0.01)$.
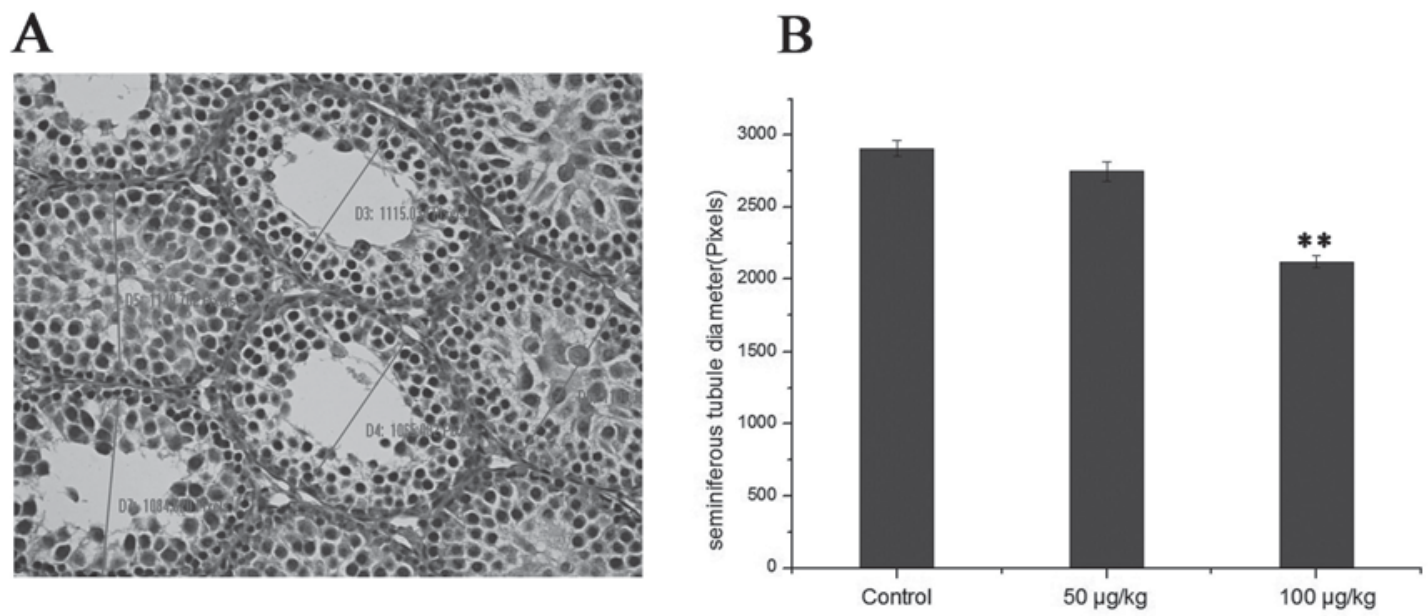

Fig. 2. Effect of MC-LR on the seminiferous tubular diameter of male rats. Samples were prepared as described in Fig. 1. Seminiferous tubular diameters were measured by Image-pro Plus. (A) A schematic diagram of diameter measurement shown in pixels. (B) Bars represent mean \pm S.E. Asterisk denotes a response that is significantly different from the control $(* * P<0.01)$. Tubular diameters showed no significant differences at $50 \mu \mathrm{g} / \mathrm{kg}$ but significantly decreased at $100 \mu \mathrm{g} / \mathrm{kg} \mathrm{MC}-$ LR.

same time the relative weight of the testes and the net weight gain mean in rats treated with $100 \mu \mathrm{g} / \mathrm{kg} \mathrm{MC}-\mathrm{LR}$ were significantly lower than those in control group. The seminiferous tubular diameter was measured to determine whether MC-LR could affect spermatogenic cells (Fig. 2). Compared to the control, the tubular diameter remained unchanged at $50 \mu \mathrm{g} / \mathrm{kg}$. But the tubular diameter was significantly decreased following treatment with $100 \mu \mathrm{g} / \mathrm{kg}$ compared with the control $(\mathrm{P}<0.01)$.

\section{The effect of MC-LR on testicular cell apoptosis}

In comparison with the control, the TUNEL positive staining revealed no significant difference in the number of apoptotic cells (arrow) at $50 \mu \mathrm{g} / \mathrm{kg} \mathrm{MC}-\mathrm{LR}$; however, there was a dramatic increase in the number of apoptotic testicular cells at the highest does of MC-LR $(100 \mu \mathrm{g} / \mathrm{kg})$. Almost all apoptotic cells were located in spermatogenic cell niches (Fig. 3).

\section{The effect of MC-LR on testicular cell proliferation}

The effect of MC-LR on testicular cell proliferation was determined by immune fluorescence staining of PCNA (Fig. 4). No major difference was observed between control and MC-LR at $50 \mu \mathrm{g} / \mathrm{kg}$. The number of proliferating cells (arrow) within the testis, which form the major spermatogenic cells, significantly decreased at the highest MC-LR concentration $(100 \mu \mathrm{g} / \mathrm{kg})$ (Fig. 4C).

\section{The effect of MC-LR on the gene expression of spermatogenic cells}

Gene-specific mRNA abundance in spermatogenic cells from rats exposed to various MC-LR concentrations was quantified by Q-PCR. As shown in Fig. 5, the mRNA levels of both TH2B and TP2 were decreased at $50 \mu \mathrm{g} / \mathrm{kg}$ MC-LR and the reduction was much more pronounced at $100 \mu \mathrm{g} / \mathrm{kg}$ exposure. The gene expression of c-kit was remarkably up-regulated to as high as 4 times of 

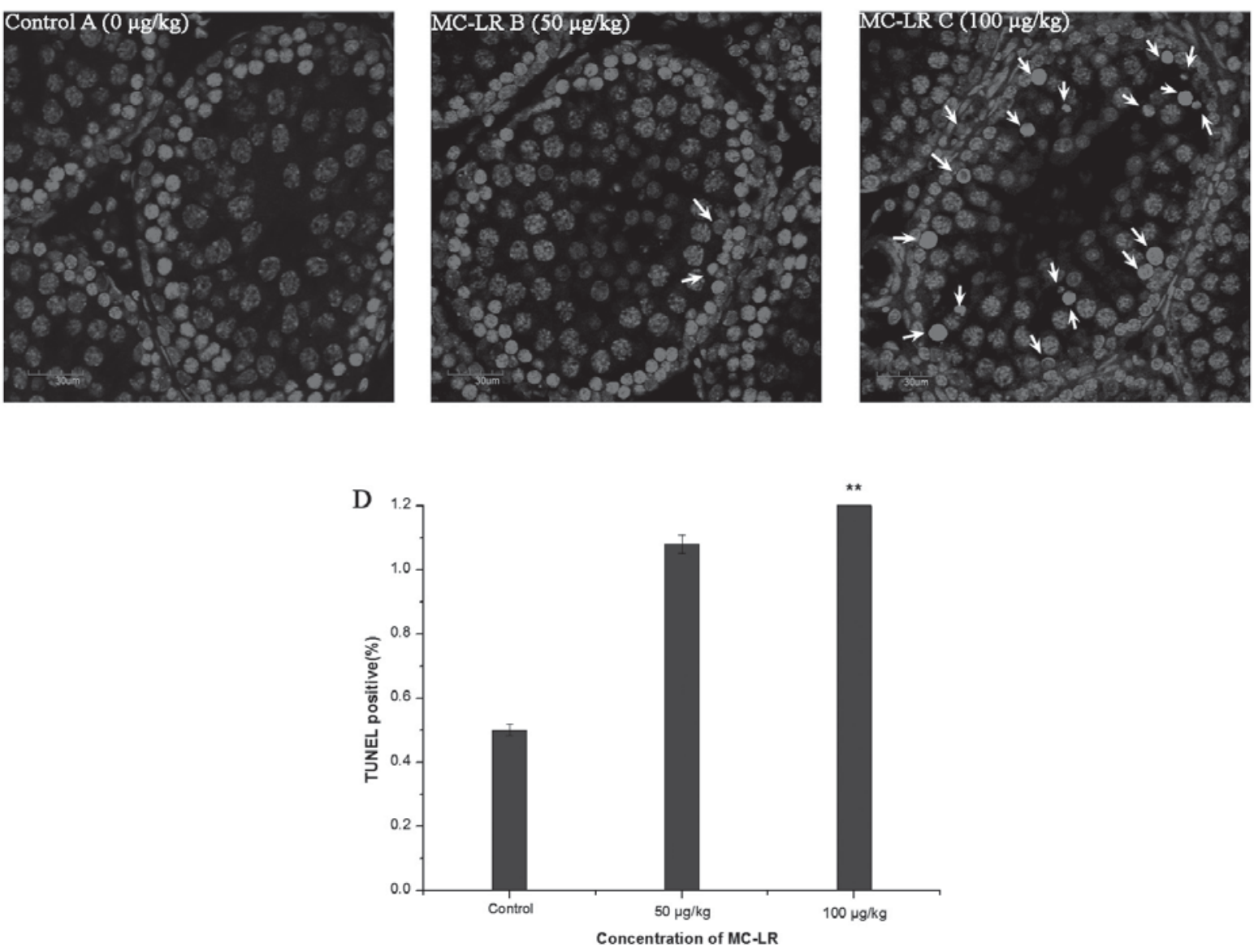

Fig. 3. Effect of MC-LR on apoptosis of spermatogenic cells. Paraffin sections were prepared from testes of rats exposed to saline (A), MC-LR at $50 \mu \mathrm{g} / \mathrm{kg}$ (B) and $100 \mu \mathrm{g} / \mathrm{kg}$ (C) for 7 days. The sections were stained by TUNEL staining. At $100 \mu \mathrm{g} / \mathrm{kg}$, the number of apoptotic spermatogenic cells (arrow) significantly increased. (Bar $=100 \mu \mathrm{m}$ ). (D) The percentage of TUNEL positive testicular cells is plotted. The TUNEL positive histogram represents the apoptosis rate in the testes of male rats after treatment with MC-LR for 7 days (mean \pm S.E.). Asterisk denotes a response that is significantly different from the control $(* * P<0.01, \mathrm{n}=5)$.

the control at $100 \mu \mathrm{g} / \mathrm{kg}$. Meanwhile, expression of TP2 was decreased by 25 times (Fig. 5).

\section{DISCUSSION}

The reduced fertility of animals and humans as a result of environmental exposure has drawn the attention of WHO, the scientific community, and the public (Swan and Elkin, 1999). Chen and his colleges found that large amounts of MCs are accumulated in the gonads and ovaries of aquatic fauna in the Chaohu Lake, China (Chen et al., 2005). MCs have been demonstrated to be toxic to the male reproductive system through acute, subacute, and chronic low-dose exposures (Chen et al., 2011;
Li et al., 2008). At low concentrations of MC-LR, the increase of sperm abnormalities is accompanied by the decrease in sperm concentration, sperm motility and testicular weight. However, the mechanisms of MC-induced sperm quality decline remain unclear. Spermatogenesis is a highly organized process involving spermatogonial proliferation, spermatocyte meiosis, and morphological alterations in spermatids (White-Cooper and Bausek, 2010). Disruption in any one of such processes will compromise sperm quality. Spermatogenic cells are the core cells in the process of spermatogenesis. These findings prompted us to investigate whether sperm abnormality was associated with injury of spermatogenic cells in the early stage after exposure to MC-LR. To address this question, the 

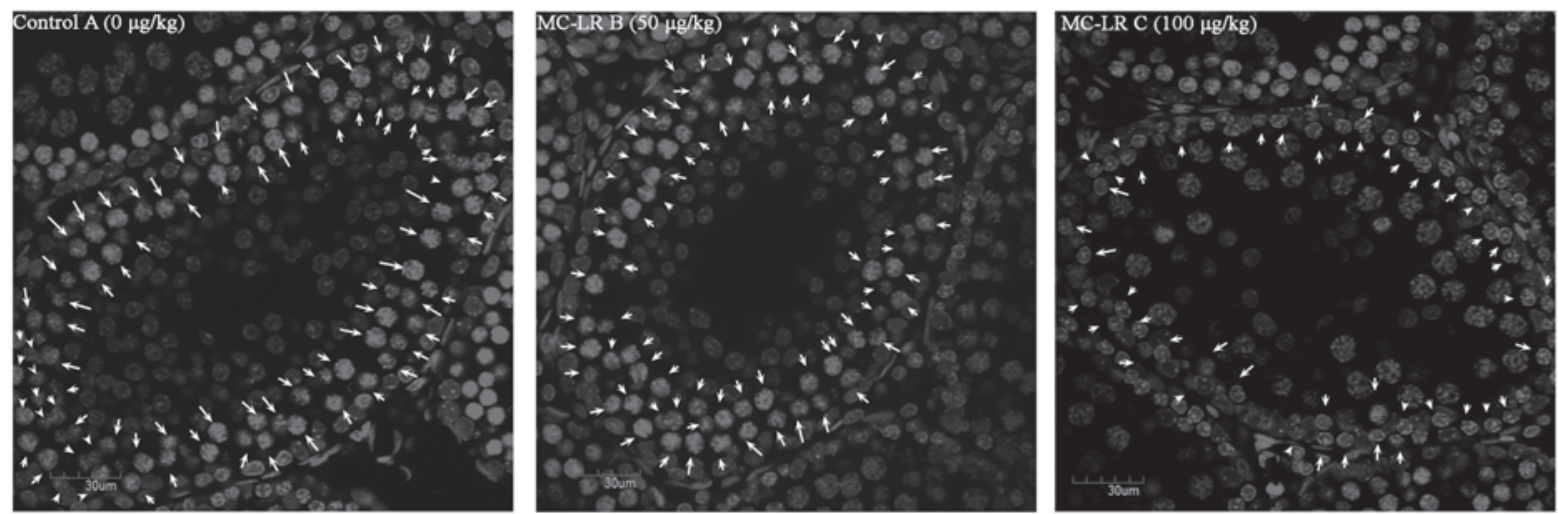

Fig. 4. Effect of MC-LR on the proliferation of spermatogenic cells. Paraffin sections were prepared from testes of rats exposed to saline (A), MC-LR at $50 \mu \mathrm{g} / \mathrm{kg}$ (B) and $100 \mu \mathrm{g} / \mathrm{kg}$ (C) for 7 days. The sections were stained by PCNA and DAPI.The number of proliferating cells (arrow) within the testis which were major spermatogenic cells significantly decreased at the highest dose of MC-LR.

C-kit

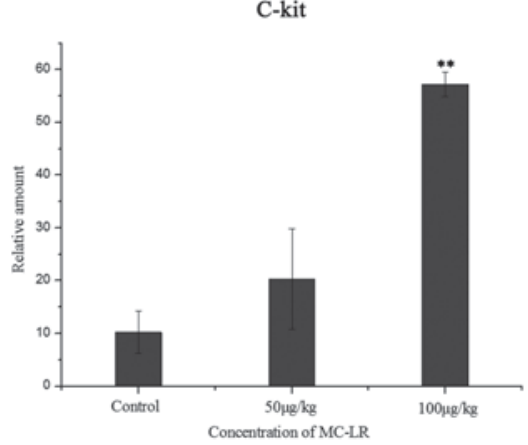

TH2B

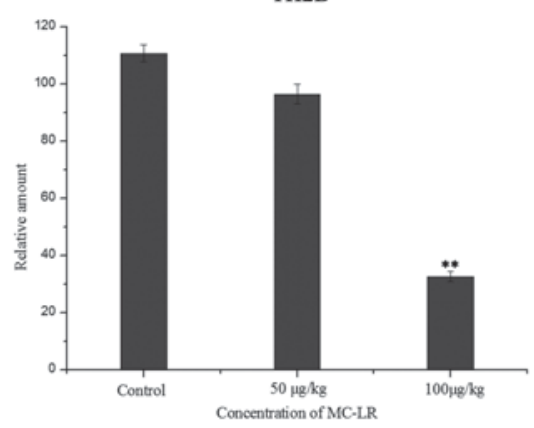

TP2

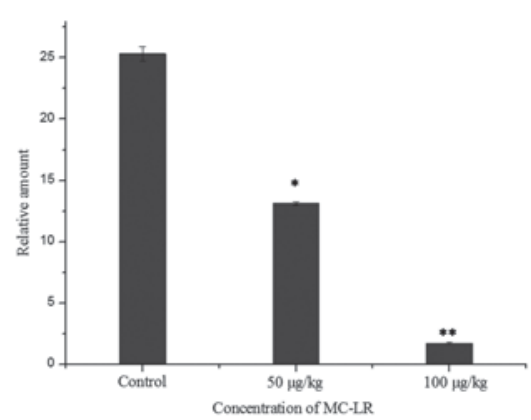

Fig. 5. Relative expression of the differentiation genes in spermatogenic cells. Tissues from testes of rats exposed to saline, MC-LR at $50 \mu \mathrm{g} / \mathrm{kg}$ and $100 \mu \mathrm{g} / \mathrm{kg}$ for 7 days were removed followed by mRNA purification, reverse transcription and Q-PCR for the detection of the c-kit, TH2B and TP2 genes. c-kit was upregulated whereas both TH2B and TP2 were down-regulated. Data are expressed as mean \pm S.E. Asterisk denotes a response that is significantly different from the control $\left({ }^{*} P<0.05\right.$, ** $P<0.01, \mathrm{n}=5)$.

reproductive toxicity of MC-LR in male rats was examined following daily exposure to 50 or $100 \mu \mathrm{g} / \mathrm{kg}$ MC-LR for 7 days based on the structural damage of the testicular seminiferous tubules. Our results were consistent with previous reports (Chen et al., 2011; Li et al., 2008). These results provide a basis for the subsequent experiments.

Male germ cell death is found most commonly in the spermatogonia, but occurs throughout spermatogenesis (Nakagawa et al., 1997). Degeneration of spermatogenic cells may be a mechanism for eliminating abnormal cells. Recent studies provide evidence that the degeneration of spermatogenic germ cells involves apoptosis
(Nakagawa et al., 1997). Spermatogenic cell apoptosis occurs spontaneously in response to endocrine disruption and exposure to various environmental agents and chemicals (Billig et al., 1995; Brinkworth et al., 1995). According to the study by Russell, there is a positive correlation between seminiferous tubular diameter and spermatogenic activity (FRANÇA LR, 1998). Degenerated tubular diameter could reflect reduced population size of spermatogenic cells. Seminiferous tubular diameter was measured using Image-pro plus to detect whether the number of spermatogenic cells would be affected after exposure to MC-LR for 7 days. Regarding tubular diameter, weight 
of the testes is also interested. The lower relative weight of the testes further pronounced the degenerated tubular diameter. Our results showed that the tubular diameter was significantly reduced in male rats exposed to MC-LR especially at $100 \mu \mathrm{g} / \mathrm{kg}$ MC-LR.

MCs are potent inhibitors of specific protein phosphatases (Craig et al., 1996). Recently, many enzymes have been reported to be critically involved in the signal transduction of MC toxicity (Campos and Vasconcelos, 2010). These enzymes are suggested to be involved in both the apoptotic effect and the tumor-promoting activity of MC-LR in hepatocytes and various other cell lines (Boaru et al., 2006; Campos and Vasconcelos, 2010). In our present fluorometric TUNEL analyses, apoptosis was observed mainly in the spermatgogenic cells within seminiferous tubules. Apoptosis dramatically increased in response to treatment with MC-LR in a dose-dependent manner. Meanwhile, no Leydig cell apoptosis was detected in the present study. Testosterone is mainly regulated by Leydig cells. However, declines of testosterone after MC-LR exposure were found in our previous study (Chen et al., 2011; Li et al., 2008). Hypothalamic-pituitary-gonadal axis is a most important pathway for endocrine regulation. Hypothalamic Gonadotrophin releasing hormone (GnRH) stimulates the release of follicle-stimulating hormone (FSH) and luteinizing hormone ( $\mathrm{LH}$ ) from the pituitary and plays a key role in the neurohormonal control of reproduction (Counis et al., 2005). LH binds to the receptors in Leydig cells to maintain general metabolic processes and steroidogenic enzymes to regulate the production of testosterone (Dufau, 1988). In vivo results showed that the levels of testosterone and GnRH decreased significantly (Wang et al., 2012). In addition, it has been proven that MC-LR has significant toxic effect on hypothalamic GnRH neurons. Furthermore, results from our lab demonstrated that MC-LR affected serum testosterone levels through damaging GnRH neurons (unpublished). Therefore, we speculate that MC-LR may affect the secretion of testosterone by damaging the hypothalamic-pituitarygonadal axis. Further investigations are required to clarify this.Further investigations are required to clarify this.

To determine whether there are any changes in the proliferation of spermatogenic cells, we used immunohistochemical staining with antibodies against PCNA, a marker for cell proliferation (Katerina Kovačevič, 2006; Nakagawa et al., 1997). Spermatogenic cells and Sertoli cells both can proliferate postnatally. Sertoli cells proliferate only postnatally and their proliferation normally ceases by day 18 (RM, 1994). A previous study has reported that all Sertoli cells are negative for this marker on day 19 postnatally (Katerina Kovačevič, 2006). Therefore, Serto- li cells were basically no longer proliferating due to rat aging around day 19 in our experiment. MC-LR treatment at $100 \mu \mathrm{g} / \mathrm{kg}$ clearly reduced PCNA positive cells which included mainly spermatogenic cells. These results were consistent with the observation in liver where cell apoptosis and proliferation are shown to be affected by MCLR (Brzuzan et al., 2009; Dias et al., 2010; Huang et al., 2011).

Biochemical studies have demonstrated that male germ cell differentiation is achieved through sequential expression of genes that can be used as markers for different types of germ cells (Dym et al., 1995; Wu et al., 2000). The c-kit receptor as a specific spermatogonia maker is used frequently in many studies (Schrans-Stassen et al., 1999). The presence of pachytene spermatocytes is confirmed by detection of the TH2B gene (Marret et al., 1998). The detection of a high level of transition protein 2 (TP2) mRNA confirms the differentiation of germ cells into round spermatids (Alfonso and Kistler, 1993; Marret et al., 1998). Therefore, c-kit, TH2B and TP2 were chosen to be differentiation markers for investigating whether MC-LR exerts toxicity on the specific stage differentiation of spermatogenic cells. We found that the gene expression levels of TH2B and TP2 were both decreased, while c-kit was increased after exposure to MC-LR. It has been reported that c-kit is highly expressed in undifferentiated spermatogonia but undetectable in differentiated spermatogonia. Elevated c-kit expression may suggest that MC-LR can block spermatogenial differentiation. Down regulation of the genes TH2B and TP2 was accompanied by reduction of pachytene spermatocytes and round spermatids, respectively. It is reported that at nanomolar concentrations MC-LR stimulates cell cycle progression in the Vero-E6 kidney cell line via the activation of the pro-proliferative ERK1/2 pathway (Dias et al., 2010). MCs affect the expression of cellular differentiation proteins in human amniotic epithelial cells (Fu et al., 2009). These findings support our data and we may infer that the formation of spermatocytes and round spermatids was hindered by MC-LR. It is speculated that MCLR influences sperm quality through its effect on spermatogonic cells. Our in vitro study on spermatogonia has showed that MC-LR might lead to cytotoxicity through oxidative stress, which may play an important role in cell injury (Zhou et al., 2012). Our in vivo experiments are more in line with the natural exposure, which confirms the in vitro findings regarding the reproductive toxicity of MC-LR on spermatogonia. It is suggested that MCs can cause damage to Sertoli cells directly through the Fas/ FasL system in vivo (Xiong et al., 2009). We may also hypothesize that MC-LR may also damage spermatogen- 
Toxic effects of microcystin-LR on spermatogenic cells

ic cells via poisoning Sertoli cells because these cells provide nutrition and support to spermatogenic cells in various developmental stages.

In conclusion, we confirmed that MC-LR affected the apoptosis, proliferation and differentiation of spermatogenic cells, which may present a mechanistic account for the declines in sperm quantity.

\section{ACKNOWLEDGEMENTS}

We received considerable technical assistance for this study from Feng Ying, Dongmei Li, Jiang Wu, Yang $\mathrm{Hu}$, Huiming Zhu, Xiaoling Gu, Cong Wang, Lihui Wang, Fangfang Sun, Ruoyu Wang, Xueting Wang and Chaowen Shi.

This work was supported by National Natural Science Foundation of China (30970530, 31200401, 81170054), Natural Science Foundation of Jiangsu Province of China (BK2012307, BK2011570), the National Basic Research Program of China (973 program 2010CB945103), and Open Research Fund of State Key Laboratory of Bioelectronics, Southeast University.

\section{REFERENCES}

Alfonso, P.J. and Kistler, W.S. (1993): Immunohistochemical localization of spermatid nuclear transition protein 2 in the testes of rats and mice. Biol. Reprod., 48, 522-529.

Backer, L.C., McNeel, S.V., Barber, T., Kirkpatrick, B., Williams, C., Irvin, M., Zhou, Y., Johnson, T.B., Nierenberg, K., Aubel, M., LePrell, R., Chapman, A., Foss, A., Corum, S., Hill, V.R., Kieszak, S.M. and Cheng, Y.S. (2010): Recreational exposure to microcystins during algal blooms in two California lakes. Toxicon, 55, 909-921.

Bellve, A.R., Cavicchia, J.C., Millette, C.F., O'Brien, D.A., Bhatnagar, Y.M. and Dym, M. (1977): Spermatogenic cells of the prepuberal mouse. Isolation and morphological characterization. J. Cell. Biol., 74, 68-85.

Billig, H., Furuta, I., Rivier, C., Tapanainen, J., Parvinen, M. and Hsueh, A.J. (1995): Apoptosis in testis germ cells: developmental changes in gonadotropin dependence and localization to selective tubule stages. Endocrinology, 136, 5-12.

Boaru, D.A., Dragos, N. and Schirmer, K. (2006): Microcystin-LR induced cellular effects in mammalian and fish primary hepatocyte cultures and cell lines: a comparative study. Toxicology, 218, 134-148.

Brinkworth, M.H., Weinbauer, G.F., Schlatt, S. and Nieschlag, E. (1995): Identification of male germ cells undergoing apoptosis in adult rats. J. Reprod. Fertil., 105, 25-33.

Brzuzan, P., Woźny, M., Ciesielski, S., Łuczyński, M.K., Góra, M., Kuźmiński, H. and Dobosz, S. (2009): Microcystin-LR induced apoptosis and mRNA expression of p53 and cdkn1a in liver of whitefish (Coregonus lavaretus L.). Toxicon, 54, 170-183.

Campos, A. and Vasconcelos, V. (2010): Molecular mechanisms of microcystin toxicity in animal cells. Int. J. Mol. Sci., 11, 268-
287

Carmichael, W.W., Azevedo, S.M., An, J.S., Molica, R.J., Jochimsen, E.M., Lau, S., Rinehart, K.L., Shaw, G.R. and Eaglesham, G.K. (2001): Human fatalities from cyanobacteria: chemical and biological evidence for cyanotoxins. Environ. Health. Perspect., 109, 663-668.

Chen, J. and Xie, P. (2005): Tissue distributions and seasonal dynamics of the hepatotoxic microcystins-LR and -RR in two freshwater shrimps, Palaemon modestus and Macrobrachium nipponensis, from a large shallow, eutrophic lake of the subtropical China. Toxicon, 45, 615-625.

Chen, J., Xie, P., Guo, L., Zheng, L. and Ni, L. (2005): Tissue distributions and seasonal dynamics of the hepatotoxic microcystinsLR and -RR in a freshwater snail (Bellamya aeruginosa) from a large shallow, eutrophic lake of the subtropical China. Environ. Pollut., 134, 423-430.

Chen, J., Xie, P., Li, L. and Xu, J. (2009): First identification of the hepatotoxic microcystins in the serum of a chronically exposed human population together with indication of hepatocellular damage. Toxicol. Sci., 108, 81-89.

Chen, Y., Xu, J., Li, Y. and Han, X. (2011): Decline of sperm quality and testicular function in male mice during chronic low-dose exposure to microcystin-LR. Reprod. Toxicol., 31, 551-557.

Counis, R., Laverrière, J.N., Garrel, G., Bleux, C., Cohen-Tannoudji, J., Lerrant, Y., Kottler, M.L. and Magre, S. (2005): Gonadotropin-releasing hormone and the control of gonadotrope function. Reproduction, nutrition, development, 45, 243-254.

Craig, M., Luu, H.A., McCready, T.L., Williams, D., Andersen, R.J. and Holmes, C.F. (1996): Molecular mechanisms underlying he interaction of motuporin and microcystins with type- 1 and type2A protein phosphatases. Biochem. Cell. Biol., 74, 569-578.

Dawson, R.M. (1998): The toxicology of microcystins. Toxicon, 36, 953-962.

Dias, E., Matos, P., Pereira, P., Batoreu, M.C., Silva, M.J. and Jordan, P. (2010): Microcystin-LR activates the ERK1/2 kinases and stimulates the proliferation of the monkey kidney-derived cell line Vero-E6. Toxicol. In Vitro, 24, 1689-1695.

Dietrich, D. and Hoeger, S. (2005): Guidance values for microcystins in water and cyanobacterial supplement products (bluegreen algal supplements): a reasonable or misguided approach? Toxicol. Appl. Pharmacol., 203, 273-289.

Dufau, M.L. (1988): Endocrine regulation and communicating functions of the Leydig cell. Annual review of physiology, 50, 483508

Dym, M., Jia, M.C., Dirami, G., Price, J.M., Rabin, S.J., Mocchetti, I. and Ravindranath, N. (1995): Expression of c-kit receptor and its autophosphorylation in immature rat type $\mathrm{A}$ spermatogonia. Biol. Reprod., 52, 8-19.

FRANÇA LR, R.L. (1998): The testis of domestic mammals. In:MARTINEZ-GARCIA F, REGADERA J (eds) Male reproduction - a multidisciplinary overview. Madrid: Churchill Comunications, 198-219.

Fu, W., Yu, Y. and Xu, L. (2009): Identification of temporal differentially expressed protein responses to microcystin in human amniotic epithelial cells. Chem. Res. Toxicol., 22, 41-51.

Harada, K. (1999): Recen Advances of Toxic Cyanobacteria Researches. J. Health Sci., 45, 150-165.

Hermann Fromme, A.K., Rita Krause and Dieter Führling (2000): Occurrence of cyanobacterial toxins - microcystins and anatoxin-a - in Berlin water bodies with implications to human health and regulations. Environmental Toxicology, 15, 120-130.

Huang, P., Zheng, Q. and Xu, L.H. (2011): The apoptotic effect of 
oral administration of microcystin-RR on mice liver. Environ. Toxicol., 26, 443-452.

Hudder, A., Song, W., O'Shea, K.E. and Walsh, P.J. (2007): Toxicogenomic evaluation of microcystin-LR treated with ultrasonic irradiation. Toxicol. Appl. Pharmacol., 220, 357-364.

Katerina Kovačevič, T.B. and Gregor Majdič (2006): Reduced seminiferous tubule diameter in mice neonatally exposed to perfume. Slovenian veterinary research, 43, 177-183.

Li, Y. and Han, X. (2012): Microcystin-LR causes cytotoxicity effects in rat testicular Sertoli cells. Environ. Toxicol. Pharmacol., 33, 318-326.

Li, Y., Sheng, J., Sha, J. and Han, X. (2008): The toxic effects of microcystin-LR on the reproductive system of male rats in vivo and in vitro. Reprod. Toxicol., 26, 239-245.

Marret, C., Avallet, O., Perrard-Sapori, M.H. and Durand, P. (1998): Localization and quantitative expression of mRNAs encoding the testis-specific histone TH2B, the phosphoprotein p19, the transition proteins 1 and 2 during pubertal development and throughout the spermatogenic cycle of the rat. Mol. Reprod. Dev., 51, 22-35.

Miura, G.A., Robinson, N.A., Lawrence, W.B. and Pace, J.G. (1991): Hepatotoxicity of microcystin-LR in fed and fasted rats. Toxicon, 29, 337-346.

Nakagawa, S., Nakamura, N., Fujioka, M. and Mori, C. (1997): Spermatogenic cell apoptosis induced by mitomycin $\mathrm{C}$ in the mouse testis. Toxicol. Appl. Pharmacol., 147, 204-213.

RM, S. (1994): Regulation of Spermatogenesis. Physiology of Reproduction, 1363-1434.

Schrans-Stassen, B.H., van de Kant, H.J., de Rooij, D.G. and van Pelt, A.M. (1999): Differential expression of c-kit in mouse undifferentiated and differentiating type A spermatogonia. Endocrinology, 140, 5894-5900.

Sohoni, P., Tyler, C.R., Hurd, K., Caunter, J., Hetheridge, M., Williams, T., Woods, C., Evans, M., Toy, R., Gargas, M. and Sumpter, J.P. (2001): Reproductive effects of long-term exposure to Bisphenol A in the fathead minnow (Pimephales promelas). Environ. Sci. Technol., 35, 2917-2925.

Svechnikov, K., Izzo, G., Landreh, L., Weisser, J. and Soder, O. (2010): Endocrine disruptors and Leydig cell function. J.
Biomed. Biotechnol., 2010.

Svircev, Z., Baltic, V., Gantar, M., Jukovic, M., Stojanovic, D. and Baltic, M. (2010): Molecular aspects of microcystin-induced hepatotoxicity and hepatocarcinogenesis. J. Environ. Sci. Health C Environ. Carcinog. Ecotoxicol. Rev., 28, 39-59.

Swan, S.H. and Elkin, E.P. (1999): Declining semen quality: can the past inform the present? Bioessays, 21, 614-621.

Tapanainen, J.S., Tilly, J.L., Vihko, K.K. and Hsueh, A.J. (1993): Hormonal control of apoptotic cell death in the testis: gonadotropins and androgens as testicular cell survival factors. Mol. Endocrinol., 7, 643-650.

Wang, M., Wang, D., Lin, L. and Hong, H. (2010): Protein profiles in zebrafish (Danio rerio) brains exposed to chronic microcystinLR. Chemosphere, 81, 716-724.

Wang, X., Ying, F., Chen, Y. and Han, X. (2012): Microcystin (-LR) affects hormones level of male mice by damaging hypothalamicpituitary system. Toxicon, 59, 205-214.

White-Cooper, H. and Bausek, N. (2010): Evolution and spermatogenesis. Philos. Trans. R. Soc. Lond. B. Biol. Sci., 365, 14651480 .

WHO (2004): Guidelines for Drinking-Water Quality, vol. 1. Recommendations, 3rd edition. World Health Organization Publishing, Geneva, Switzerland.

Wu, J.Y., Ribar, T.J., Cummings, D.E., Burton, K.A., McKnight, G.S. and Means, A.R. (2000): Spermiogenesis and exchange of basic nuclear proteins are impaired in male germ cells lacking Camk4. Nat. Genet., 25, 448-452.

Xie, L., Xie, P., Ozawa, K., Honma, T., Yokoyama, A. and Park, H.D. (2004): Dynamics of microcystins-LR and -RR in the phytoplanktivorous silver carp in a sub-chronic toxicity experiment. Environ. Pollut., 127, 431-439.

Xiong, Q., Xie, P., Li, H., Hao, L., Li, G., Qiu, T. and Liu, Y. (2009): Involvement of Fas/FasL system in apoptotic signaling in testicular germ cells of male Wistar rats injected i.v. with microcystins. Toxicon, 54, 1-7.

Zhou, Y., Yuan, J., Wu, J. and Han, X. (2012): The toxic effects of microcystin-LR on rat spermatogonia in vitro. Toxicol. Lett., 212, 48-56 